\title{
Post-resuscitation shock: recent advances in pathophysiology and treatment
}

\author{
Mathieu Jozwiak ${ }^{1,2^{*}} \mathbb{D}$, Wulfran Bougouin ${ }^{3,4,5,10}$, Guillaume Geri ${ }^{6,7,8,10}$, David Grimaldi ${ }^{9,10}$ and Alain Cariou ${ }^{1,2,4,5,10}$
}

\begin{abstract}
A post-resuscitation shock occurs in 50-70\% of patients who had a cardiac arrest. It is an early and transient complication of the post-resuscitation phase, which frequently leads to multiple-organ failure and high mortality. The pathophysiology of post-resuscitation shock is complex and results from the whole-body ischemia-reperfusion process provoked by the sequence of circulatory arrest, resuscitation manoeuvers and return of spontaneous circulation, combining a myocardial dysfunction and sepsis features, such as vasoplegia, hypovolemia and endothelial dysfunction. Similarly to septic shock, the hemodynamic management of post-resuscitation shock is based on an early and aggressive hemodynamic management, including fluid administration, vasopressors and/or inotropes. Norepinephrine should be considered as the first-line vasopressor in order to avoid arrhythmogenic effects of other catecholamines and dobutamine is the most established inotrope in this situation. Importantly, the optimal mean arterial pressure target during the post-resuscitation shock still remains unknown and may probably vary according to patients. Mechanical circulatory support by extracorporeal membrane oxygenation can be necessary in the most severe patients, when the neurological prognosis is assumed to be favourable. Other symptomatic treatments include protective lung ventilation with a target of normoxia and normocapnia and targeted temperature management by avoiding the lowest temperature targets. Early coronary angiogram and coronary reperfusion must be considered in ST-elevation myocardial infarction (STEMI) patients with preserved neurological prognosis although the timing of coronary angiogram in non-STEMI patients is still a matter of debate. Further clinical research is needed in order to explore new therapeutic opportunities regarding inflammatory, hormonal and vascular dysfunction.
\end{abstract}

Keywords: Cardiac arrest, Coronary angiogram, Ischemia-reperfusion syndrome, Mean arterial pressure, Myocardial dysfunction, Targeted temperature management, Vasopressors

\section{The concept of post-resuscitation shock}

Outcome of cardiac arrest (CA) remains very poor. Over $60 \%$ of patients with out-of-hospital cardiac arrest (OHCA) will die without sustainable return of spontaneous circulation (ROSC) [1]. Among patients with sustainable ROSC, intensive care unit (ICU) mortality remains high, ranging from $60 \%[2,3]$ to $80 \%[1,4]$ of patients. Inhospital mortality after OHCA mainly results from different causes including recurrent $\mathrm{CA}$, irreversible anoxic

\footnotetext{
*Correspondence: mathieu.jozwiak@aphp.fr

1 Service de Médecine Intensive Réanimation, Hôpitaux Universitaires Paris-Centre, Hôpital Cochin, Assistance Publique-Hôpitaux de Paris, 27, rue du faubourg Saint Jacques, 75014 Paris, France

Full list of author information is available at the end of the article
}

brain damage (including brain death), as well as comorbid withdrawal of care $[5,6]$. In addition, a substantial proportion of these post-CA patients will suffer from a severe hemodynamic impairment that may worsen organ damages and may lead to death in the first hours or days. All these complications are closely related to the duration of no-flow and low-flow of CA and thus to the severity of the oxygen debt of the different organs.

The first description of this post-resuscitation shock was provided by Vladimir Negovsky more than 45 years ago [7]. In a series of animal experiments and clinical observations, he has reported a myriad of clinical and biological changes that could be observed as a consequence of the whole-body ischemia and reperfusion provoked by CA. Among these disorders, the hemodynamic 
impairment is one of the most frequent and most severe alterations. Today, it is commonly accepted that after resuscitation and ROSC, the combination of tissue hypoperfusion and arterial hypotension requiring a continuous infusion of vasopressor may correspond to the most pragmatic definition of this shock [3, 8, 9]. Using this definition, the incidence of the post-resuscitation shock ranges between 50 and $70 \%[3,8,9]$. In a retrospective cohort of patients admitted in ICU after an OHCA, Lemiale et al. reported a global incidence of $68 \%$, and they also identified some factors (male gender, shockable rhythm, time to ROSC) associated with its occurrence [3].

In-hospital mortality attributable to this post-resuscitation shock varies between 20 and $55 \%$ [2, 3, 5] and most often results from multiple-organ failure, including (1) myocardial dysfunction in up to two third of patients [10], (2) acute renal failure in $10-80 \%$ of patients according to the definition used with a pooled incidence of $37 \%$ [11], requiring renal replacement therapy in one third of patients [12] and associated with long-term occurrence of chronic kidney disease [13], (3) hypoxic hepatitis in almost $15 \%$ of patients $[14,15]$ and (4) metabolic acidosis in up to $90 \%$ of patients [16]. All these organ failures were shown to be associated with poor outcome in this setting.

In this review, we aimed at focusing on the recent advances in pathophysiology and treatment of postresuscitation shock.

\section{Pathophysiology of post-resuscitation shock}

The pathophysiology of post-resuscitation shock is both due to the cause of CA and to the ischemia-reperfusion syndrome, which results in a complex and multifactorial puzzle of organ dysfunctions. Whatever the aetiology of $\mathrm{CA}$, the post-resuscitation shock is mainly a combination of myocardial dysfunction, vasoplegia and hypovolemia.

\section{Myocardial dysfunction}

In a pivotal study combining angiographic data and pulmonary artery catheter monitoring, Laurent and colleagues prospectively described the hemodynamic profile of consecutive patients after CA from cardiac origin before ICU admission at the time of initial left ventricular angiography and within the first $72 \mathrm{~h}$ of ICU stay [17]. When left ventricular angiography was performed, the ejection fraction was reduced in all patients, whereas filling pressure was increased in patients with hemodynamic instability but low to normal in patients without hemodynamic instability. Few hours after ICU admission, the cardiac index was found to be decreased with low or normal filling pressure in all patients, suggesting hypovolemia. Thereafter, the cardiac index gradually improved with a return to normal values within $24 \mathrm{~h}$, whereas filling pressure remained unchanged over time. Despite improvement of cardiac index, all patients required large amount of fluid administration and high doses of vasopressors within the first $72 \mathrm{~h}$ to maintain acceptable mean arterial pressure (MAP) level [17]. On the whole, these observations were suggestive of an early and severe myocardial dysfunction, usually regressive within $48 \mathrm{~h}$, associated with a vasoplegia.

Using echocardiography, it has been shown that this post-resuscitation myocardial dysfunction is very common, concerning up to $70 \%$ of the patients $[10,18]$. The most common pattern is an early and transient systolic and diastolic left ventricular dysfunction [17], which can be considered as a model of myocardial stunning following the ischemia-reperfusion syndrome [19]. Of course, this myocardial dysfunction is very common when CA results from a coronary occlusion. However, this myocardial dysfunction may be worsened by repeated defibrillations (especially when using a monophasic and high-energy current), and may also be partly considered as an "adrenergic cardiopathy", as illustrated by the independent association between the epinephrine dose administered during cardiopulmonary resuscitation and the severity of the cardiac dysfunction [20].

\section{Vasoplegia}

Regarding the vasoplegia that is commonly observed as a consequence of the ischemia-reperfusion syndrome, two mechanisms are mainly suspected on the basis on prospective human studies. First, neutrophils accumulation, neutrophil-endothelial interaction and neutrophils activation in microvessels following global ischemia and reperfusion lead to endothelial cell dysfunction [21]. The latter increases the transduction of inducible NOsynthase, which in turn induces a relaxation of vascular smooth muscle cells and promotes the activation of the coagulation cascade [22]. Second, the reactive oxygen species generated by the ischemia-reperfusion syndrome activate the innate immune cells. It leads to an increase in inflammatory cytokines release and inducible NO-synthase expression, both worsening the endothelial dysfunction and thus vasoplegia [23, 24]. Since these two mechanisms are very similar to those involved in the pathophysiology of sepsis, the post-resuscitation shock is frequently considered as "a sepsis-like syndrome". In addition, an authentic sepsis may also contribute to this hemodynamic profile as infectious complications are very common at this stage [25].

\section{Hypovolemia}

Hypovolemia after CA is common but often undertreated, because of the fear of fluid overload in these patients with potential myocardial dysfunction. It results 
from vasoplegia (relative hypovolemia due to the mismatch between contents and container), from the capillary-leak syndrome in the most severe patients with prolonged resuscitation before ROSC and/or under extracorporeal life support (ECLS) [26] and in a later phase, from the third compartment syndrome related to ileus and intestinal injury.

\section{Splanchnic dysfunction and endotoxemia}

Some human and prospective studies have suggested that gut injury could also contribute to the vasoplegia observed in the post-resuscitation shock through its ability to provoke or worsen a systemic inflammatory response [27-29]. Indeed, in post-CA patients, markers of intestinal injury are increased and endotoxemia is frequent $[27,28]$, this latter being associated with the severity of vasoplegia [29]. However, its incidence is still unknown and the relationship between post-resuscitation shock and gut injury is complex, as the two are closely intertwined.

\section{Hormonal dysfunction}

A relative adrenal insufficiency could also participate to the vasoplegia observed during the post-resuscitation shock. Pène and colleagues prospectively performed corticotropin-stimulation test in consecutive post-CA patients admitted in ICU and they observed that 52\% of these patients had a relative adrenal insufficiency that was associated with shock-related mortality [30]. These findings were confirmed by other teams [31, 32], highlighting the concept of both relative adrenal insufficiency and adrenal reserve exhaustion (as observed in patients with septic shock). In addition, the hypothalamic release of arginine-vasopressin seems to be impaired in patients after CA [33], also contributing to vasoplegia.

Importantly, there is an interindividual variability in the respective weight of the different mechanisms described above in the pathophysiology of post-resuscitation shock. Nevertheless, all are closely interplayed and result in a vicious circle that self-perpetuates it (Fig. 1).

\section{Management of post-resuscitation shock Symptomatic treatments \\ Early-goal directed therapy}

Similarities between septic and post-resuscitation shock led some authors to advocate for post-resuscitation shock an early-goal directed therapy strategy including hemodynamic resuscitation and therapeutic hypothermia [34, 35]. The hemodynamic resuscitation that is proposed is based on an aggressive step-by-step strategy including fluids, vasopressors, inotropes and blood transfusion, in order to target predefined MAP level and to normalize the central venous oxygen saturation, used as a surrogate of oxygen delivery within the first hours of therapy. Preliminary results from an exploratory study including 20 patients without systematic assessment of cardiac function suggested that this early-goal directed therapy did not improve mortality after comparison with matched historic controls [34]. A recent multicentre and randomized study confirmed that such an early-goal directed

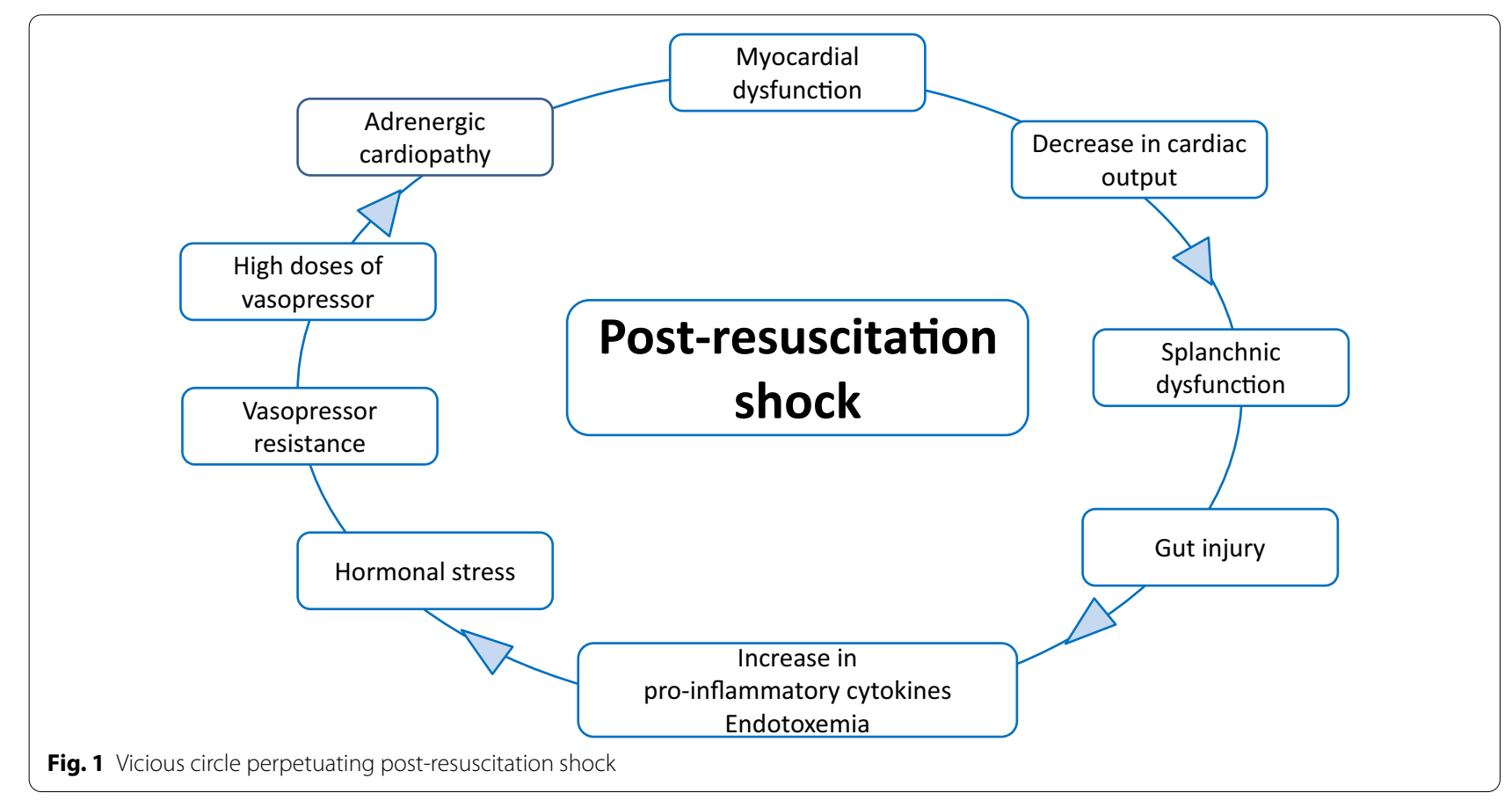


therapy strategy was neither shown to improve mortality nor to limit the extent of anoxic brain damage or neurological outcome despite an improvement in cerebral oxygenation [35]. Nevertheless, it might be reasonable to use such a strategy in post-resuscitation shock in order to maintain an adequate organ perfusion (Fig. 2).

\section{Vasopressors and inotropic drugs}

Besides fluid administration, the hemodynamic management of post-resuscitation shock is mostly based on vasopressors because of the severe vasoplegia and vasodilation, in combination with inotropes when post-resuscitation myocardial dysfunction is present (Fig. 2).

Norepinephrine should be considered as the first-line vasopressor, in order to avoid arrhythmogenic effects of other catecholamines. Regarding inotropes, dobutamine is the most established treatment in this situation [36, 37]. These two animal studies showed that dobutamine successfully overcome the global systolic and diastolic left ventricular dysfunction resulting from prolonged CA [36, 37]. In addition, the most effective dose would be $5 \mu \mathrm{g} /$ $\mathrm{kg} / \mathrm{min}$ : a lower dose would be inefficient and a higher dose would increase in a too large extent the myocardial oxygen consumption [37]. Importantly, this threshold value of $5 \mu \mathrm{g} / \mathrm{kg} / \mathrm{min}$ could not necessarily be transposed in humans and the potential detrimental effects of higher dose of dobutamine deserve further studies.

Levosimandan could also be an interesting alternative to dobutamine in this setting, as suggested by an animal study [38], as well as phosphodiesterase inhibitor such as milrinone [20]. Nevertheless, nothing was done in this field since nearly one decade and both treatments still require further clinical validation and are not recommended for the management of post-resuscitation shock so far.

\section{Target for mean arterial pressure level}

Because arterial hypotension is associated with poor neurological outcomes in patients after CA [39] and because the autoregulation of cerebral blood flow may be impaired after ROSC [40], the MAP level is an important therapeutic goal in patients with post-resuscitation shock. In this regard, several observational studies have suggested that maintenance of higher MAP levels was associated with a better brain tissue oxygenation [41], an improvement in survival $[42,43]$ and a better neurological outcome [44]. In a recent multicenter and randomized study (COMACARE study), it has been shown in 120 comatose patients after OHCA that, targeting a low-normal $(65-75 \mathrm{mmHg})$ or a high-normal (80$100 \mathrm{mmHg}$ ) MAP level for the first $36 \mathrm{~h}$ after ICU admission neither affect the neuron-specific enolase (NSE) serum level nor mortality or neurological outcomes [45]. However, targeting a high-normal MAP level was recently shown to decrease troponin release as a marker of myocardial injury [46]. Thus, although it is currently recommended that hemodynamic treatments should be guided by arterial pressure, the optimal MAP level still

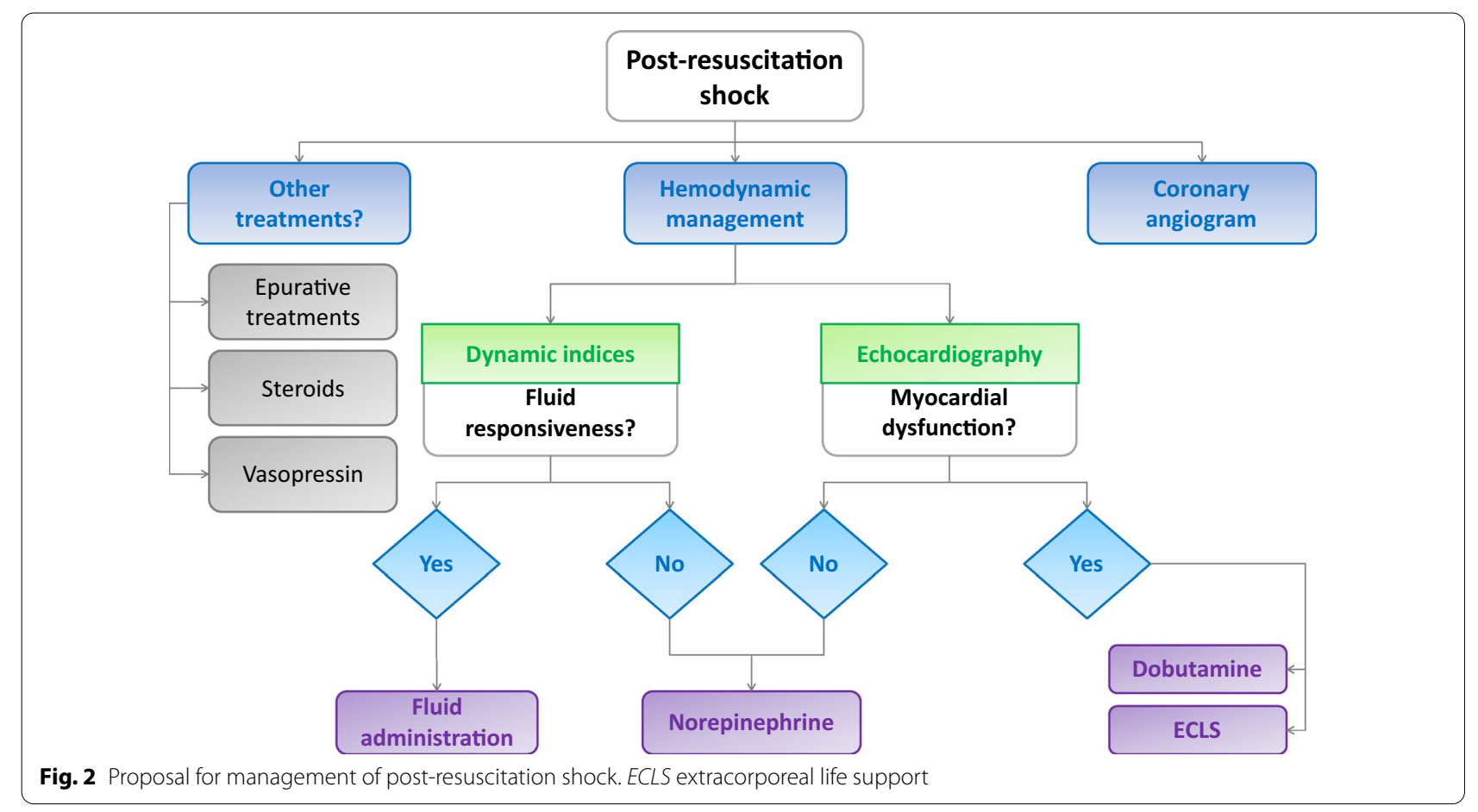


remains unknown and may probably vary according to patients [47].

\section{Ventilatory management}

A vast majority of post-CA patients are mechanically ventilated, according to current guidelines [47]. Regarding protective lung ventilation strategies, it has been shown in a retrospective study that lower tidal volumes $(\leq 6 \mathrm{~mL} / \mathrm{kg})$ were independently associated with favorable neurocognitive outcome, more ventilator-free days and more shock-free days [48]. Regarding the positive end-expiratory pressure (PEEP) level, a secondary analysis of three international prospective, observational and multicenter studies including 812 patients mechanically ventilated after CA, showed that the PEEP level increased from $3.5 \pm 3$ to $6.5 \pm 3 \mathrm{cmH} 2 \mathrm{O}$ between 1998 and 2010 and that lower PEEP levels were independently associated with the occurrence of ICU-acquired pneumonia [49]. Thus, although no study has specifically investigated this issue, a PEEP level between 4 and $8 \mathrm{cmH} 20$ [47], or higher in patients with acute respiratory distress syndrome [50], seems to be rationale. To summarize, it seems to be reasonable to consider protective lung ventilation in such patients who are exposed to a marked inflammatory response.

Hypoxemia and hypercapnia should be strictly controlled, since both may contribute to secondary brain injury, even in patients receiving ECLS [51]. However, the role of oxygenation remains still debated: the results of an exploratory post-hoc substudy of the Target Temperature Management (TTM) trial suggested that hyperoxemia and hypoxemia were not associated with poor neurological outcome and increase in biomarker of brain injury [52], whereas some retrospective and/or meta-analysis of experimental and clinical studies found that hyperoxia could be linked to poor neurological outcome [53] through oxidative stress and potential direct pulmonary and cardiovascular toxicity of oxygen [54]. Finally, preliminary experimental $[55,56]$ and human $[57$, 58] studies might suggest a potential interest of hyperbaric oxygenation as a curative treatment of reperfusion injury, with a decrease in neuronal death $[55,56]$ and an improvement of neurological outcomes [55-57] or cognitive functions [58] after CA not related to carbon monoxide poisoning or gas embolism.

In the multicenter and randomized COMACARE study, targeting a low-normal or a normal-high range in partial pressure of arterial carbon dioxide $\left(\mathrm{PaCO}_{2}\right)$ and oxygen $\left(\mathrm{PaO}_{2}\right)$ during the first $36 \mathrm{~h}$ after ICU admission did not affect NSE serum level [59]. However, highnormal $\mathrm{PaCO}_{2}(5.8-6.0 \mathrm{kPa})$ and moderate hyperoxia $\left(\mathrm{PaO}_{2}: 20-25 \mathrm{kPa}\right)$ resulted in better cerebral oxygenation [59]. Another large multicenter and randomized trial comparing normocapnia and mild hypercapnia in patients after OHCA is still ongoing (NCT03114033).

At that time, current guidelines recommend to target normoxia and normocapnia during the first $72 \mathrm{~h}$ [47].

\section{Targeted temperature management}

Targeted temperature management (TTM) is currently recommended in patients after OHCA with initial shockable rhythm who remain comatose after ROSC and is suggested in patients after OHCA with non-shockable rhythm or after in-hospital CA with any initial rhythm who remain comatose after ROSC, for at least $24 \mathrm{~h} \mathrm{[47,}$ $60,61]$. TTM should be started immediately at ICU admission [62]. However, the optimal target temperature $[63,64]$, the optimal duration [65] of TTM as well as the cooling procedures [66-68] are still matter of debate.

Beyond neuroprotective effects [69], TTM might also have cardioprotective effects, especially in patients experiencing post-resuscitation myocardial dysfunction [20]. Currently, there is no sufficient data to contraindicate TTM in patients with post-resuscitation shock. However, when TTM is used, there are some arguments that suggest avoiding lowest temperature targets. In a sub-study of the TTM trial, TTM at $33^{\circ} \mathrm{C}$ was associated with more frequent hemodynamic alterations (decreased heart rate, elevated levels of lactate, and need for increased vasopressor support) compared with TTM at $36{ }^{\circ} \mathrm{C}$ [70].

\section{Specific treatments \\ Coronary reperfusion}

There is a large consensus for considering acute coronary disease as a frequent cause of CA in adult patients [71, 72]. By analogy with the management of other acute coronary syndromes, the most common strategy is to perform a coronary angiogram (CAG) as soon as possible, since many observational studies reported a significant association between early percutaneous coronary intervention and improved outcome after OHCA [73-75]. Current guidelines argue for a large use of early CAG in these patients $[47,76]$. Once the interest of percutaneous coronary intervention in CA of ischemic cause is universally acknowledged, there are several unsolved issues. Among these issues, selection of the best candidates and optimal timing for CAG are the most debated. Regarding the indication, the decision for early CAG should be based on a panel of arguments encompassing previous medical history, warning symptoms before arrest, initial cardiac rhythm, electrocardiographic pattern after ROSC, and biomarkers if available. In addition, recent retrospective data highlight the interest of focusing coronary interventions for patients with preserved neurological status [77]. Regarding the timing, there is a consensus for early CAG (i.e., as soon as possible after 
hospital arrival) in ST-elevation myocardial infarction (STEMI) patients with preserved neurological prognosis, since this "scoop and run" strategy offers the benefit of both immediate diagnosis and treatment and may avoid secondary cardio-circulatory deterioration related to untreated coronary occlusion [47]. By contrast, a "wait and see" strategy (delayed CAG) may be proposed in patients without evidence of STEMI [78]. Thus, Lemkes and colleagues showed in a multicenter and randomized controlled trial that the survival of patients who had CA without signs of STEMI was similar regardless the timing of CAG. In addition, a delayed strategy avoided a significant number of useless CAG [78]. These two strategies (early versus delayed CAG in non-STEMI patients) are currently evaluated in several ongoing studies (DISCO NCT02309151, COUPE NCT02641626, TOMAHAWK NCT02750462, PEARL NCT02387398, NCT02587494, EMERGE NCT02876458), which should be helpful for establishing future guidelines.

\section{Extracorporeal life support}

Mechanical circulatory support can be necessary in the most severe forms of post-resuscitation shock, when the neurological prognosis is assumed to be favourable. Several technics have been proposed, such as Impella [79], or intra-aortic balloon pump [80]. However, the post-resuscitation myocardial dysfunction can be very severe and global $[10,20]$ with unpredictable severity, up to refractory cardiogenic shock. For these reasons, veno-arterial extra-corporeal membrane oxygenation is the most commonly employed ECLS technic in the post-resuscitation shock [81].

The main issue is to identify the most suitable patients with post-resuscitation shock eligible for ECLS. Bascom and colleagues have proposed to use the "CREST score" (Table 1) for early identification of patients carrying the highest risk of circulatory-related death after CA, who could, therefore, be elective candidates for ECLS [82]. It has also been shown that in patients with post-resuscitation shock treated by ECLS, admission SOFA score $<14$, initial shockable rhythm and international normalized ratio $<2.4$ as well as initial arterial $\mathrm{pH}$ (odds ratio $=1.7$ per 0.1 increase) and implantation of ECLS later than $24 \mathrm{~h}$ after ROSC were associated with survival and thus could be useful triage tools in such patients [83, 84]. Interestingly, $25-28 \%$ of these ECLS patients survived to hospital discharge with favourable neurological and longterm outcome [83, 84], supporting the use of ECLS in carefully selected patients with post-resuscitation shock [85].

Beyond hemodynamic severity, the neurological prognosis should be also considered before the decision of ECLS in patients with post-resuscitation shock. Several scores have been proposed to assess neurological prognosis after OHCA [77, 86-88] (Table 1) and could be useful to guide the therapeutic strategy in patients experiencing CA [77].

To summarize, ECLS should be considered as a bridgeto-recovery only in the most severe patients with postresuscitation shock with preserved neurological status, assessed by some selected prognostic factors or specific scores (Table 1).

\section{Epurative treatments}

Regards to the important release of inflammatory mediators and cytokines in patients with post-resuscitation shock, animal studies have suggested that an early blood removal of inflammatory mediators could be associated with an improvement in hemodynamics and outcome $[89,90]$. However, inflammatory mediators are relatively large molecules and it is thus unlikely that the membranes used for conventional renal replacement therapies allow one to achieve high level of cytokines removal, conversely to other alternative extracorporeal blood purification therapies. In this regard, Laurent and colleagues prospectively assessed the effects of high-volume hemofiltration, a technique known to allow a better removal of cytokines, in consecutive patients with post-resuscitation shock [91]. Compared to conventional renal replacement therapy, the use of high-volume hemofiltration was associated with a better survival, while there was no significant effect on the cytokines levels [91]. Such a lack of effect on cytokines removal on hemodynamics was confirmed in more recent animal [92] or human studies [93] pleading against cytokine removal in ischemia-reperfusion syndrome, whatever the epurative technique used.

This lack of effect may be explained by several mechanisms: (1) the lower cytokines level at ICU admission (compared to patients with septic shock) [22], (2) the quick decrease in cytokines level after the initial and transient increase at the time of ROSC [91, 92], and/or (3) the membrane fouling, resulting in a progressive better removal of molecules with lower molecular weights despite the use of high cut-offs membranes.

Thus, given the potential prolonged effects on hemodynamics of the inflammatory mediators and cytokines despite their very short half-life, future therapies should rather focus on agents able to block the inflammatory cascade following the release of inflammatory mediators and cytokines, than to epurative treatments.

\section{Steroids}

The use of steroids in patients with post-resuscitation shock is still debated despite the evidence for the hormonal dysfunction. Although beneficial effects of glucocorticoids administration during cardiopulmonary 
Table 1 Summarize of the different scores that can be used to select eligible patients with post-resuscitation shock to extracorporeal life support

\begin{tabular}{|c|c|c|c|c|}
\hline \multirow{2}{*}{$\begin{array}{l}\text { Scores } \\
\text { Assessment of risk of circulatory-related death }\end{array}$} & \multicolumn{4}{|l|}{ Points } \\
\hline & & & & \\
\hline \multicolumn{5}{|l|}{ CREST score } \\
\hline History of coronary artery disease & \multicolumn{4}{|l|}{1} \\
\hline Non-shockable rhythm & \multicolumn{4}{|l|}{1} \\
\hline LVEF at time of admission $<30 \%$ & \multicolumn{4}{|l|}{1} \\
\hline Shock at presentation & \multicolumn{4}{|l|}{1} \\
\hline Ischemic time $>25 \mathrm{~min}$ & \multicolumn{4}{|l|}{1} \\
\hline \multicolumn{5}{|l|}{ Assessment of neurological prognosis } \\
\hline \multicolumn{5}{|l|}{ CAHPscore } \\
\hline Age & \multicolumn{4}{|c|}{$1.1 \times($ age -10$)$} \\
\hline Setting & \multicolumn{4}{|c|}{0 if public setting and 24 if home } \\
\hline Initial Rhythm & \multicolumn{4}{|c|}{0 if shockable and 27 if non-shockable } \\
\hline Collapse-BLS duration (min) & \multicolumn{4}{|c|}{$2.8 \times$ duration } \\
\hline BLS-ROSC duration (min) & \multicolumn{4}{|c|}{$0.8 \times$ duration } \\
\hline $\mathrm{pH}$ & \multicolumn{4}{|c|}{$585-77 \times \mathrm{pH}$} \\
\hline Epinephrine dose during ressuscitation (total) & \multicolumn{4}{|c|}{0 if $0 \mathrm{mg}$ and 27 if 1 or $2 \mathrm{mg}$} \\
\hline \multicolumn{5}{|l|}{ OHCA score } \\
\hline Ventricular fibrillation or tachycardia & \multirow{4}{*}{\multicolumn{4}{|c|}{$\begin{array}{l}-13 \text { if the initial recorded rhythm is VF or ventricular tachycardia } \\
+6 \times \ln \text { (no-flow interval) } \\
+9 \times \ln \text { (low-flow interval) } \\
-1434 / \text { serum creatinine } \\
+10 \times \ln \text { (arterial lactate) }\end{array}$}} \\
\hline No-flow interval (min) & & & & \\
\hline Low-flow interval (min) & & & & \\
\hline Serum creatinine $(\mu \mathrm{mol} / \mathrm{L})$ & & & & \\
\hline \multicolumn{5}{|l|}{ Lactate (mmol/L) } \\
\hline \multicolumn{5}{|l|}{ CAST score } \\
\hline & 0 & 1 & 2 & 3 \\
\hline Initial rhythm & Shockable & Non-shockable & - & - \\
\hline Witness/ROSC time (min) & $<20 \min$ & $\geq 20 \min$ & No witness & - \\
\hline $\mathrm{pH}$ & $\geq 7.31$ & $7.16-7.30$ & $7.01-7.15$ & $\leq 7.00$ \\
\hline Lactate (mmol/L) & $\leq 5.0$ & $5.1-10.0$ & $10.1-14.0$ & $\geq 14.1$ \\
\hline Motor component of Glasgow coma scale & $\geq 2$ & 1 & - & - \\
\hline Gray matter attenuation to white matter attenuation ratio & $\geq 1.201$ & $1.151-1.200$ & $\leq 1.150$ & - \\
\hline Albumin (g/dL) & $\geq 3.6$ & $3.1-3.5$ & $\leq 3.0$ & - \\
\hline Hemoglobin (g/dL) & $\geq 13.1$ & $11.1-13.0$ & & $\leq 11.0$ \\
\hline
\end{tabular}

For the CREST score, ischemic time was defined as estimated time from cardiac arrest to return of spontaneous circulation

$L V E F$ left ventricular ejection fraction, $B L S$ basic life support, $L n$ natural logarithm, ROSC return of spontaneous circulation

resuscitation have been suggested by retrospective or pilot studies [94, 95], only a few studies have focused on the impact of corticosteroids administration in successfully resuscitated patients. In a randomized controlled trial by Mentzelopoulos and colleagues [96] comparing a strategy combining vasopressin, methylprednisolone and epinephrine versus epinephrine alone, patients who were successfully resuscitated received either a stressdose of hydrocortisone (300 mg daily for 7 days) or saline. Interestingly, the administration of hydrocortisone (at least one dose) improved survival to hospital discharge with favorable neurological status, suggesting a potential benefit of steroids. Nevertheless, because multiple interventions were concomitantly used, it is difficult to affirm the effect of hydrocortisone itself on outcome. More recently, Donnino et al. evaluated the interest of hydrocortisone administration (300 mg daily for 7 days) in a randomized, double-blind, placebo-controlled trial including 50 patients with refractory post-resuscitation shock [97]. Compared to placebo administration, no beneficial effect of hydrocortisone on mortality, time to shock reversal or shock reversal, or neurological outcome was observed. However, patients with documented adrenal insufficiency who received hydrocortisone tended to achieve shock reversal more frequently than those receiving placebo [97]. 
In a recent work, Tsai et al. have shown in a retrospective analysis of the Taiwan National Health Insurance Research Database that the administration of steroids during the post-CA period was associated with better survival to hospital discharge and 1-year survival in patients receiving low-dose of steroids $(<50 \mathrm{mg}$ daily equivalent prednisone, i.e., about $200 \mathrm{mg} /$ day of hydrocortisone) only [98]. Conversely, higher doses of steroids could even be associated with worse outcomes than in patients not receiving steroids [98]. Despite the retrospective design of the study and the fact that these results come from health insurance databases (with many potential confounders), the administration of low-dose of hydrocortisone in patients with post-resuscitation shock might be of interest, especially in patients with associated relative adrenal insufficiency. Further randomized trials are needed to clarify the potential interest of steroids in patients with post- resuscitation shock.

\section{New perspectives}

Although the impairment of the hypothalamic release of arginine-vasopressin contributes to the vasoplegia of the post-resuscitation shock [33], only few data are available regarding the potential interest of vasopressin administration in patients with post-resuscitation shock $[96,99]$ and only one study investigated the potential isolated effect of vasopressin administration in such patients [99]. Thus, Mayr and colleagues retrospectively reported the hemodynamic effects of arginine-vasopressin administration in 23 patients with post-resuscitation shock unresponsive to hemodynamic therapy including fluids, norepinephrine, epinephrine and milrinone. Argininevasopressin administration significantly increased MAP and decreased the catecholamines requirement and blood lactate level [99]. Despite the retrospective design of the study and the small number of patients, these results should encourage to further evaluate the effects of arginine-vasopressin, possibly in combination with low-dose of hydrocortisone, in an attempt to achieve the "hormonal healing" in patients with post- resuscitation shock.

Finally, to further investigate the gut dysfunction in post-CA patients, an ongoing study (ENTRACT study, NCT02349074) aims at determining the incidence of upper gastro-intestinal tract ischemia by performing systematic gastroscopy in all patients experiencing $\mathrm{CA}$.

\section{Conclusion}

The post-resuscitation shock results from the wholebody ischemia-reperfusion process provoked by the sequence of circulatory arrest, resuscitation manoeuvers and return of spontaneous circulation. It is an early and transient complication of the post-resuscitation phase, which frequently results in multiple-organ failure and high mortality. Its pathophysiology is complex and multifactorial, combining a myocardial dysfunction and characteristics common to sepsis, such as vasoplegia, hypovolemia and endothelial dysfunction. Treatment is based on an early and aggressive hemodynamic management, including ECLS in the most severe patients, associated with coronary reperfusion when needed. Further clinical research is needed in order to explore new therapeutic opportunities regarding inflammatory, hormonal and vascular dysfunction.

\section{Abbreviations \\ CA: Cardiac arrest; CAG: Coronary angiogram; ECLS: Extracorporeal life support; ICU: Intensive care unit; MAP: Mean arterial pressure; NSE: Neuron-specific enolase; OHCA: Out-of-hospital cardiac arrest; $\mathrm{PaCO}_{2}$ : Arterial carbon dioxide partial pressure; $\mathrm{PaO}_{2}$ : Arterial oxygen partial pressure; PEEP: Positive end- expiratory pressure; ROSC: Return of spontaneous circulation; TTM: Targeted temperature management.}

\section{Acknowledgements \\ Not applicable.}

\section{Authors' contributions}

MJ, WB, GG, DG and AC drafted the manuscript. All authors read and approved the final manuscript.

Funding

None.

Availability of data and materials

Not applicable.

Ethics approval and consent to participate

Not applicable.

Consent for publication

Not applicable.

Competing interests

The authors declare that they have no competing interests.

\section{Author details}

${ }^{1}$ Service de Médecine Intensive Réanimation, Hôpitaux Universitaires ParisCentre, Hôpital Cochin, Assistance Publique-Hôpitaux de Paris, 27, rue du faubourg Saint Jacques, 75014 Paris, France. ${ }^{2}$ Université de Paris, Paris, France. ${ }^{3}$ Service de Médecine Intensive Réanimation, Hôpital Privé Jacques Cartier, Ramsay Générale de Santé, Massy, France. ${ }^{4}$ INSERM U970, Paris-Cardiovascular-Research-Center, Paris, France. ${ }^{5}$ Paris Sudden-Death-Expertise-Centre, Paris, France. ${ }^{6}$ Service de Médecine Intensive Réanimation, Hôpital Universitaire Ambroise Paré, Assistance Publique-Hôpitaux de Paris, Boulogne-Billancourt, France. ${ }^{7}$ Université Paris-Saclay, Paris, France. ${ }^{8}$ INSERM UMR1018, Centre de Recherche en Epidémiologie Et Santé Des Populations, Villejuif, France. ${ }^{9}$ Service de Soins Intensifs CUB-Erasme, Université Libre de Bruxelles (ULB), Bruxelles, Belgium. ${ }^{10}$ AfterROSC Network Group, Paris, France.

Received: 4 October 2020 Accepted: 2 December 2020

Published online: 14 December 2020

\section{References}

1. Bougouin W, Lamhaut L, Marijon E, Jost D, Dumas F, Deye N, et al. Characteristics and prognosis of sudden cardiac death in Greater Paris: population-based approach from the Paris Sudden Death Expertise Center (Paris-SDEC). Intensive Care Med. 2014:40(6):846-54. 
2. Laver S, Farrow C, Turner D, Nolan J. Mode of death after admission to an intensive care unit following cardiac arrest. Intensive Care Med. 2004;30(11):2126-8.

3. Lemiale V, Dumas F, Mongardon N, Giovanetti O, Charpentier J, Chiche $J \mathrm{D}$, et al. Intensive care unit mortality after cardiac arrest: the relative contribution of shock and brain injury in a large cohort. Intensive Care Med. 2013;39(11):1972-80.

4. Kilgannon JH, Roberts BW, Reihl LR, Chansky ME, Jones AE, Dellinger RP, et al. Early arterial hypotension is common in the post-cardiac arrest syndrome and associated with increased in-hospital mortality. Resuscitation. 2008;79(3):410-6.

5. Witten L, Gardner R, Holmberg MJ, Wiberg S, Moskowitz A, Mehta S, et al. Reasons for death in patients successfully resuscitated from out-of-hospital and in-hospital cardiac arrest. Resuscitation. 2019;136:93-9.

6. Cour M, Turc J, Madelaine T, Argaud L. Risk factors for progression toward brain death after out-of-hospital cardiac arrest. Ann Intensive Care. 2019;9(1):45.

7. Negovsky VA. The second step in resuscitation - the treatment of the 'post-resuscitation disease.' Resuscitation. 1972;1(1):1-7.

8. Dumas F, Bougouin W, Geri G, Lamhaut L, Rosencher J, Pene F, et al. Emergency percutaneous coronary intervention in post-cardiac arrest patients without ST-segment elevation pattern: insights from the PROCAT II Registry. JACC Cardiovasc Interv. 2016;9(10):1011-8.

9. Argaud L, Cour M, Dubien PY, Giraud F, Jossan C, Riche B, et al. Effect of cyclosporine in nonshockable out-of-hospital cardiac arrest: the CYRUS randomized clinical trial. JAMA Cardiol. 2016;1(5):557-65.

10. Ruiz-Bailen M, Aguayo de Hoyos E, Ruiz-Navarro S, Diaz-Castellanos MA, Rucabado-Aguilar L, Gomez-Jimenez FJ, et al. Reversible myocardial dysfunction after cardiopulmonary resuscitation. Resuscitation. 2005;66(2):175-81.

11. Sandroni C, Dell'anna AM, Tujjar O, Geri G, Cariou A, Taccone FS. Acute kidney injury after cardiac arrest: a systematic review and meta-analysis of clinical studies. Minerva Anestesiol. 2016;82(9):989-99.

12. Geri G, Guillemet L, Dumas F, Charpentier J, Antona M, Lemiale V, et al. Acute kidney injury after out-of-hospital cardiac arrest: risk factors and prognosis in a large cohort. Intensive Care Med. 2015;41(7):1273-80.

13. Jamme M, Ait Hamou Z, Ben Hadj Salem O, Guillemet L, Bougouin W, Pene $\mathrm{F}$, et al. Long term renal recovery in survivors after OHCA. Resuscitation. 2019;141:144-50.

14. Oh SH, Kim HJ, Park KN, Kim SH, Kim YM, Youn CS, et al. Hypoxic hepatitis in survivors of out-of-hospital cardiac arrest. Am J Emerg Med. 2015;33(9):1166-70

15. Champigneulle B, Geri G, Bougouin W, Dumas F, Arnaout M, Zafrani L, et al. Hypoxic hepatitis after out-of-hospital cardiac arrest: Incidence, determinants and prognosis. Resuscitation. 2016;103:60-5.

16. Jamme M, Ben Hadj Salem O, Guillemet L, Dupland P, Bougouin W, Charpentier J, et al. Severe metabolic acidosis after out-of-hospital cardiac arrest: risk factors and association with outcome. Ann Intensive Care. 2018;8(1):62.

17. Laurent I, Monchi M, Chiche JD, Joly LM, Spaulding C, Bourgeois B, et al. Reversible myocardial dysfunction in survivors of out-of-hospital cardiac arrest. J Am Coll Cardiol. 2002;40(12):2110-6.

18. Anderson RJ, Jinadasa SP, Hsu L, Ghafouri TB, Tyagi S, Joshua J, et al. Shock subtypes by left ventricular ejection fraction following out-of-hospital cardiac arrest. Crit Care. 2018;22(1):162.

19. Kern KB, Hilwig RW, Rhee KH, Berg RA. Myocardial dysfunction after resuscitation from cardiac arrest: an example of global myocardial stunning. J Am Coll Cardiol. 1996;28(1):232-40.

20. Bougouin W, Cariou A. Management of postcardiac arrest myocardial dysfunction. Curr Opin Crit Care. 2013;19(3):195-201.

21. Gando S, Nanzaki S, Morimoto Y, Kobayashi S, Kemmotsu O. Out-ofhospital cardiac arrest increases soluble vascular endothelial adhesion molecules and neutrophil elastase associated with endothelial injury. Intensive Care Med. 2000;26(1):38-44.

22. Adrie C, Monchi M, Laurent I, Um S, Yan SB, Thuong M, et al. Coagulopathy after successful cardiopulmonary resuscitation following cardiac arrest: implication of the protein C anticoagulant pathway. J Am Coll Cardiol. 2005:46(1):21-8

23. Adrie C, Adib-Conquy M, Laurent I, Monchi M, Vinsonneau C, Fitting C, et al. Successful cardiopulmonary resuscitation after cardiac arrest as a "sepsis-like" syndrome. Circulation. 2002;106(5):562-8.
24. Adrie C, Laurent I, Monchi M, Cariou A, Dhainaou JF, Spaulding C. Postresuscitation disease after cardiac arrest: a sepsis-like syndrome? Curr Opin Crit Care. 2004;10(3):208-12.

25. Mongardon N, Perbet S, Lemiale V, Dumas F, Poupet H, Charpentier J, et al. Infectious complications in out-of-hospital cardiac arrest patients in the therapeutic hypothermia era. Crit Care Med. 2011;39(6):1359-64.

26. Megarbane B, Leprince P, Deye N, Resiere D, Guerrier G, Rettab S, et al. Emergency feasibility in medical intensive care unit of extracorporeal life support for refractory cardiac arrest. Intensive Care Med. 2007;33(5):758-64.

27. Grimaldi D, Guivarch E, Neveux N, Fichet J, Pene F, Marx JS, et al. Markers of intestinal injury are associated with endotoxemia in successfully resuscitated patients. Resuscitation. 2013;84(1):60-5.

28. Piton G, Belin N, Barrot L, Belon F, Cypriani B, Navellou JC, et al. Enterocyte damage: a piece in the puzzle of post-cardiac arrest syndrome. Shock. 2015:44(5):438-44

29. Grimaldi D, Sauneuf B, Guivarch E, Ricome S, Geri G, Charpentier J, et al. High level of endotoxemia following out-of-hospital cardiac arrest is associated with severity and duration of postcardiac arrest shock. Crit Care Med. 2015;43(12):2597-604.

30. Pene F, Hyvernat H, Mallet V, Cariou A, Carli P, Spaulding C, et al. Prognostic value of relative adrenal insufficiency after out-of-hospital cardiac arrest. Intensive Care Med. 2005;31(5):627-33.

31. Hekimian G, Baugnon T, Thuong M, Monchi M, Dabbane H, Jaby D, et al. Cortisol levels and adrenal reserve after successful cardiac arrest resuscitation. Shock. 2004;22(2):116-9.

32. Kim JJ, Lim YS, Shin JH, Yang HJ, Kim JK, Hyun SY, et al. Relative adrena insufficiency after cardiac arrest: impact on postresuscitation disease outcome. Am J Emerg Med. 2006;24(6):684-8.

33. Lindner KH, Haak T, Keller A, Bothner U, Lurie KG. Release of endogenous vasopressors during and after cardiopulmonary resuscitation. Heart. 1996;75(2):145-50.

34. Gaieski DF, Band RA, Abella BS, Neumar RW, Fuchs BD, Kolansky DM, et al. Early goal-directed hemodynamic optimization combined with therapeutic hypothermia in comatose survivors of out-of-hospital cardiac arrest. Resuscitation. 2009:80(4):418-24.

35. Ameloot K, De Deyne C, Eertmans W, Ferdinande B, Dupont M, Palmers PJ, et al. Early goal-directed haemodynamic optimization of cerebral oxygenation in comatose survivors after cardiac arrest: the neuroprotect post-cardiac arrest trial. Eur Heart J. 2019:40(22):1804-14.

36. Kern KB, Hilwig RW, Berg RA, Rhee KH, Sanders AB, Otto CW, et al. Postresuscitation left ventricular systolic and diastolic dysfunction: treatment with dobutamine. Circulation. 1997;95(12):2610-3.

37. Vasquez A, Kern KB, Hilwig RW, Heidenreich J, Berg RA, Ewy GA. Optimal dosing of dobutamine for treating post-resuscitation left ventricular dysfunction. Resuscitation. 2004;61(2):199-207.

38. Huang L, Weil MH, Tang W, Sun S, Wang J. Comparison between dobutamine and levosimendan for management of postresuscitation myocardial dysfunction. Crit Care Med. 2005;33(3):487-91.

39. Bhate TD, McDonald B, Sekhon MS, Griesdale DE. Association between blood pressure and outcomes in patients after cardiac arrest: a systematic review. Resuscitation. 2015;97:1-6.

40. Sundgreen C, Larsen FS, Herzog TM, Knudsen GM, Boesgaard S, Aldershvile J. Autoregulation of cerebral blood flow in patients resuscitated from cardiac arrest. Stroke. 2001;32(1):128-32.

41. Sekhon MS, Gooderham P, Menon DK, Brasher PMA, Foster D, Cardim D, et al. The burden of brain hypoxia and optimal mean arterial pressure in patients with hypoxic ischemic brain injury after cardiac arrest. Crit Care Med. 2019:47(7):960-9.

42. Ameloot K, Meex I, Genbrugge C, Jans F, Boer W, Verhaert D, et al. Hemodynamic targets during therapeutic hypothermia after cardiac arrest: a prospective observational study. Resuscitation. 2015;91:56-62.

43. Russo JJ, James TE, Hibbert B, Yousef A, Osborne C, Wells GA, et al. Impact of mean arterial pressure on clinical outcomes in comatose survivors of out-of-hospital cardiac arrest: insights from the University of Ottawa Heart Institute Regional Cardiac Arrest Registry (CAPITAL-CARe). Resuscitation. 2017;113:27-32.

44. Roberts BW, Kilgannon JH, Hunter BR, Puskarich MA, Shea L, Donnino M, et al. Association between elevated mean arterial blood pressure and neurologic outcome after resuscitation from cardiac arrest: results from a multicenter prospective cohort study. Crit Care Med. 2019;47(1):93-100. 
45. Jakkula P, Pettila V, Skrifvars MB, Hastbacka J, Loisa P, Tiainen M, et al. Targeting low-normal or high-normal mean arterial pressure after cardiac arrest and resuscitation: a randomised pilot trial. Intensive Care Med. 2018;44(12):2091-101.

46. Ameloot K, Jakkula P, Hastbacka J, Reinikainen M, Pettila V, Loisa P, et al. Optimum blood pressure in patients with shock after acute myocardial infarction and cardiac arrest. J Am Coll Cardiol. 2020;76(7):812-24.

47. Nolan JP, Soar J, Cariou A, Cronberg T, Moulaert VR, Deakin CD, et al. European Resuscitation Council and European Society of Intensive Care Medicine guidelines for post-resuscitation care 2015: section 5 of the European Resuscitation Council guidelines for resuscitation 2015. Resuscitation. 2015;95:202-22.

48. Beitler JR, Ghafouri TB, Jinadasa SP, Mueller A, Hsu L, Anderson RJ, et al. Favorable neurocognitive outcome with low tidal volume ventilation after cardiac arrest. Am J Respir Crit Care Med. 2017;195(9):1 198-206.

49. Sutherasan Y, Penuelas O, Muriel A, Vargas M, Frutos-Vivar F, Brunetti I, et al. Management and outcome of mechanically ventilated patients after cardiac arrest. Crit Care. 2015;19:215.

50. Papazian L, Aubron C, Brochard L, Chiche JD, Combes A, Dreyfuss D, et al. Formal guidelines: management of acute respiratory distress syndrome. Ann Intensive Care. 2019;9(1):69.

51. Chang WT, Wang CH, Lai CH, Yu HY, Chou NK, Wang CH, et al. Optimal arterial blood oxygen tension in the early postresuscitation phase of extracorporeal cardiopulmonary resuscitation: a 15-year retrospective observational study. Crit Care Med. 2019;47(11):1549-56.

52. Ebner F, Ullen S, Aneman A, Cronberg T, Mattsson N, Friberg H, et al. Associations between partial pressure of oxygen and neurological outcome in out-of-hospital cardiac arrest patients: an explorative analysis of a randomized trial. Crit Care. 2019;23(1):30.

53. Youn CS, Park KN, Kim SH, Lee BK, Oh SH, Jeung KW, et al. The cumulative partial pressure of arterial oxygen is associated with neurological outcomes after cardiac arrest treated with targeted temperature management. Crit Care Med. 2018;46(4):e279-85.

54. Llitjos JF, Mira JP, Duranteau J, Cariou A. Hyperoxia toxicity after cardiac arrest: what is the evidence? Ann Intensive Care. 2016;6(1):23.

55. Malek M, Duszczyk M, Zyszkowski M, Ziembowicz A, Salinska E. Hyperbaric oxygen and hyperbaric air treatment result in comparable neuronal death reduction and improved behavioral outcome after transient forebrain ischemia in the gerbil. Exp Brain Res. 2013;224(1):1-14.

56. Rosenthal RE, Silbergleit R, Hof PR, Haywood Y, Fiskum G. Hyperbaric oxygen reduces neuronal death and improves neurological outcome after canine cardiac arrest. Stroke. 2003;34(5):1311-6.

57. Koch A, Vermeulen-Cranch DM. The use of hyperbaric oxygen following cardiac arrest. Br J Anaesth. 1962;34:738-40.

58. Hadanny A, Golan H, Fishlev G, Bechor Y, Volkov O, Suzin G, et al. Hyperbaric oxygen can induce neuroplasticity and improve cognitive functions of patients suffering from anoxic brain damage. Restor Neurol Neurosci. 2015;33(4):471-86.

59. Jakkula P, Reinikainen M, Hastbacka J, Loisa P, Tiainen M, Pettila V, et al. Targeting two different levels of both arterial carbon dioxide and arterial oxygen after cardiac arrest and resuscitation: a randomised pilot trial. Intensive Care Med. 2018;44(12):2112-21.

60. Cariou A, Payen JF, Asehnoune K, Audibert G, Botte A, Brissaud O, et al. Targeted temperature management in the ICU: guidelines from a French expert panel. Ann Intensive Care. 2017;7(1):70.

61. Lascarrou JB, Merdji H, Le Gouge A, Colin G, Grillet G, Girardie P, et al. Targeted temperature management for cardiac arrest with nonshockable rhythm. N Engl J Med. 2019;381(24):2327-37.

62. Oddo M, Bracard S, Cariou A, Chanques G, Citerio G, Clerckx B, et al. Update in neurocritical care: a summary of the 2018 Paris international conference of the French Society of Intensive Care. Ann Intensive Care. 2019;9(1):47.

63. Lopez-de-Sa E, Juarez M, Armada E, Sanchez-Salado JC, Sanchez PL, Loma-Osorio P, et al. A multicentre randomized pilot trial on the effectiveness of different levels of cooling in comatose survivors of out-of-hospital cardiac arrest: the FROST-I trial. Intensive Care Med. 2018:44(11):1807-15.

64. Okazaki T, Hifumi T, Kawakita K, Kuroda Y, Japanese Association for Acute Medicine out-of-hospital cardiac arrest r. Targeted temperature management guided by the severity of hyperlactatemia for out-of-hospital cardiac arrest patients: a post hoc analysis of a nationwide, multicenter prospective registry. Ann Intensive Care. 2019;9(1):127.
65. Kirkegaard H, Soreide E, de Haas I, Pettila V, Taccone FS, Arus U, et al. Targeted temperature management for 48 vs 24 hours and neurologic outcome after out-of-hospital cardiac arrest: a randomized clinical trial. JAMA. 2017;318(4):341-50.

66. Deye N, Cariou A, Girardie P, Pichon N, Megarbane B, Midez P, et al. Endovascular versus external targeted temperature management for patients with out-of-hospital cardiac arrest: a randomized, controlled study. Circulation. 2015;132(3):182-93.

67. De Fazio C, Skrifvars MB, Soreide E, Creteur J, Grejs AM, Kjaergaard J, et al. Intravascular versus surface cooling for targeted temperature management after out-of-hospital cardiac arrest: an analysis of the TTH48 trial. Crit Care. 2019;23(1):61.

68. Nordberg P, Taccone FS, Truhlar A, Forsberg S, Hollenberg J, Jonsson M, et al. Effect of trans-nasal evaporative intra-arrest cooling on functional neurologic outcome in out-of-hospital cardiac arrest: the PRINCESS randomized clinical trial. JAMA. 2019;321(17):1677-85.

69. Mongardon N, Dumas F, Ricome S, Grimaldi D, Hissem T, Pene F, et al. Postcardiac arrest syndrome: from immediate resuscitation to long-term outcome. Ann Intensive Care. 2011;1 (1):45.

70. Bro-Jeppesen J, Annborn M, Hassager C, Wise MP, Pelosi P, Nielsen N, et al. Hemodynamics and vasopressor support during targeted temperature management at $33^{\circ} \mathrm{C}$ versus $36^{\circ} \mathrm{C}$ after out-of-hospital cardiac arrest: a post hoc study of the target temperature management trial* ${ }^{*}$. Crit Care Med. 2015;43(2):318-27.

71. Larsen JM, Ravkilde J. Acute coronary angiography in patients resuscitated from out-of-hospital cardiac arrest-a systematic review and metaanalysis. Resuscitation. 2012;83(12):1427-33.

72. Geri G, Passouant O, Dumas F, Bougouin W, Champigneulle B, Arnaout $\mathrm{M}$, et al. Etiological diagnoses of out-of-hospital cardiac arrest survivors admitted to the intensive care unit: Insights from a French registry. Resuscitation. 2017:117:66-72.

73. Spaulding CM, Joly LM, Rosenberg A, Monchi M, Weber SN, Dhainaut JF, et al. Immediate coronary angiography in survivors of out-of-hospital cardiac arrest. N Engl J Med. 1997;336(23):1629-33.

74. Dumas F, Cariou A, Manzo-Silberman S, Grimaldi D, Vivien B, Rosencher $J$, et al. Immediate percutaneous coronary intervention is associated with better survival after out-of-hospital cardiac arrest: insights from the PROCAT (Parisian Region Out of hospital Cardiac ArresT) registry. Circ Cardiovasc Interv. 2010;3(3):200-7.

75. Dumas F, White L, Stubbs BA, Cariou A, Rea TD. Long-term prognosis following resuscitation from out of hospital cardiac arrest: role of percutaneous coronary intervention and therapeutic hypothermia. J Am Coll Cardiol. 2012;60(1):21-7.

76. Callaway CW, Donnino MW, Fink EL, Geocadin RG, Golan E, Kern KB, et al. Part 8: post-cardiac arrest care: 2015 American Heart association guidelines update for cardiopulmonary resuscitation and emergency cardiovascular care. Circulation. 2015;132(18 Suppl 2):S465-82.

77. Bougouin W, Dumas F, Karam N, Maupain C, Marijon E, Lamhaut L, et al. Should we perform an immediate coronary angiogram in all patients after cardiac arrest? Insights from a large French Registry. JACC Cardiovasc Interv. 2018;11(3):249-56.

78. Lemkes JS, Janssens GN, van der Hoeven NW, Jewbali LSD, Dubois EA, Meuwissen $\mathrm{M}$, et al. Coronary angiography after cardiac arrest without STsegment elevation. N Engl J Med. 2019;380(15):1397-407.

79. Manzo-Silberman S, Fichet J, Mathonnet A, Varenne O, Ricome S, Chaib A, et al. Percutaneous left ventricular assistance in post cardiac arrest shock: comparison of intra aortic blood pump and IMPELLA Recover LP2.5. Resuscitation. 2013;84(5):609-15.

80. Thiele H, Zeymer U, Neumann FJ, Ferenc M, Olbrich HG, Hausleiter J, et al. Intraaortic balloon support for myocardial infarction with cardiogenic shock. N Engl J Med. 2012;367(14):1287-96.

81. Combes A, Brodie D, Chen YS, Fan E, Henriques JPS, Hodgson C, et al. The ICM research agenda on extracorporeal life support. Intensive Care Med. 2017:43(9):1306-18.

82. Bascom KE, Dziodzio J, Vasaiwala S, Mooney M, Patel N, McPherson J, et al. Derivation and validation of the CREST model for very early prediction of circulatory etiology death in patients without ST-segment-elevation myocardial infarction after cardiac arrest. Circulation. 2018;137(3):273-82.

83. Pineton de Chambrun M, Brechot N, Lebreton G, Schmidt M, Hekimian G, Demondion $\mathrm{P}$, et al. Venoarterial extracorporeal membrane oxygenation 
for refractory cardiogenic shock post-cardiac arrest. Intensive Care Med. 2016;42(12):1999-2007.

84. Bougouin W, Aissaoui N, Combes A, Deye N, Lamhaut L, Jost D, et al. Postcardiac arrest shock treated with veno-arterial extracorporeal membrane oxygenation: an observational study and propensity-score analysis. Resuscitation. 2017;110:126-32.

85. Yannopoulos D, Bartos JA, Raveendran G, Conterato M, Frascone RJ, Trembley A, et al. Coronary artery disease in patients with out-ofhospital refractory ventricular fibrillation cardiac arrest. J Am Coll Cardiol. 2017;70(9):1109-17.

86. Adrie C, Cariou A, Mourvillier B, Laurent I, Dabbane H, Hantala F, et al. Predicting survival with good neurological recovery at hospital admission after successful resuscitation of out-of-hospital cardiac arrest: the OHCA score. Eur Heart J. 2006;27(23):2840-5.

87. Maupain C, Bougouin W, Lamhaut L, Deye N, Diehl JL, Geri G, et al. The CAHP (Cardiac Arrest Hospital Prognosis) score: a tool for risk stratification after out-of-hospital cardiac arrest. Eur Heart J. 2016;37(42):3222-8.

88. Nishikimi M, Matsuda N, Matsui K, Takahashi K, Ejima T, Liu K, et al. CAST: a new score for early prediction of neurological outcomes after cardiac arrest before therapeutic hypothermia with high accuracy. Intensive Care Med. 2016;42(12):2106-7.

89. Grootendorst $A F$, van Bommel EF, van Leengoed $L A$, van Zanten $A R$, Huipen $\mathrm{HJ}$, Groeneveld AB. Infusion of ultrafiltrate from endotoxemic pigs depresses myocardial performance in normal pigs. J Crit Care. 1993;8(3):161-9.

90. Grootendorst AF, van Bommel EF, van Leengoed LA, Nabuurs M, Bouman CS, Groeneveld AB. High volume hemofiltration improves hemodynamics and survival of pigs exposed to gut ischemia and reperfusion. Shock. 1994;2(1):72-8.

91. Laurent I, Adrie C, Vinsonneau C, Cariou A, Chiche JD, Ohanessian A, et al. High-volume hemofiltration after out-of-hospital cardiac arrest: a randomized study. J Am Coll Cardiol. 2005;46(3):432-7.
92. Shinozaki K, Lampe JW, Kim J, Yin T, Da T, Oda S, et al. The effects of early high-volume hemofiltration on prolonged cardiac arrest in rats with reperfusion by cardiopulmonary bypass: a randomized controlled animal study. Intensive Care Med Exp. 2016;4(1):25.

93. Geri G, Grimaldi D, Seguin T, Lamhaut L, Marin N, Chiche JD, et al. Hemodynamic efficiency of hemodialysis treatment with high cut-off membrane during the early period of post-resuscitation shock: The HYPERDIA trial. Resuscitation. 2019;140:170-7.

94. Tsai MS, Huang CH, Chang WT, Chen WJ, Hsu CY, Hsieh CC, et al. The effect of hydrocortisone on the outcome of out-of-hospital cardiac arrest patients: a pilot study. Am J Emerg Med. 2007;25(3):318-25.

95. Tsai MS, Chuang PY, Yu PH, Huang CH, Tang CH, Chang WT, et al. Glucocorticoid use during cardiopulmonary resuscitation may be beneficial for cardiac arrest. Int J Cardiol. 2016;222:629-35.

96. Mentzelopoulos SD, Malachias S, Chamos C, Konstantopoulos D, Ntaidou T, Papastylianou A, et al. Vasopressin, steroids, and epinephrine and neurologically favorable survival after in-hospital cardiac arrest: a randomized clinical trial. JAMA. 2013;310(3):270-9.

97. Donnino MW, Andersen LW, Berg KM, Chase M, Sherwin R, Smithline H, et al. Corticosteroid therapy in refractory shock following cardiac arrest: a randomized, double-blind, placebo-controlled, trial. Crit Care. 2016;20:82.

98. Tsai MS, Chuang PY, Huang CH, Tang CH, Yu PH, Chang WT, et al. Postarrest steroid use may improve outcomes of cardiac arrest survivors. Crit Care Med. 2019;47(2):167-75.

99. Mayr V, Luckner G, Jochberger S, Wenzel V, Ulmer H, Pajk W, et al. Arginine vasopressin in advanced cardiovascular failure during the post-resuscitation phase after cardiac arrest. Resuscitation. 2007;72(1):35-44.

\section{Publisher's Note}

Springer Nature remains neutral with regard to jurisdictional claims in published maps and institutional affiliations.

\section{Submit your manuscript to a SpringerOpen ${ }^{\odot}$ journal and benefit from:}

- Convenient online submission

- Rigorous peer review

- Open access: articles freely available online

- High visibility within the field

- Retaining the copyright to your article

Submit your next manuscript at $\boldsymbol{\nabla}$ springeropen.com 